\title{
Metrics of the ratio of functional limits of large agribusiness (regional aspect)
}

\author{
Marina Kholodova ${ }^{1 *}$, Mikhail Kabanenko ${ }^{2}$, Safura Muradova ${ }^{2}$, Lyudmila Dubrova ${ }^{3}$, Olga \\ Bruzhukova $^{4}$ \\ ${ }^{1}$ Federal Rostov Agricultural Research Centre (FSBSI FRARC), Institutskaya str. 1, p. Rassvet, \\ Aksay district, Rostov region, 346735, Russia \\ ${ }^{2}$ Southern University, Mikhail Nagibin Ave., 3A/47, Rostov on Don, 344068, Russia \\ ${ }^{3}$ Don State Technical University, Gagarin sq., 1, Rostov on Don, 344003, Russia \\ ${ }^{4}$ All-Russian State University of justice (RLA of the Ministry of justice of Russia), str. 9 \\ Line/Sovetskaya, 2/32. Rostov-on-Don, 344000, Russia
}

\begin{abstract}
The purpose of the article is to study the problem of measuring the functional limits of integrated agricultural formations in the region. The conducted research allowed us to determine the optimal size of a large agribusiness in the region. In particular, for the current economic conditions of the region, the most effective type of integration associations, their optimal size in terms of area and the average number of employees were determined. The conceptual provisions of the proposed algorithm and its practical conclusions can be used by regional authorities in order to form an optimal agricultural structure. The identification of the optimal size of modern integrated formations will contribute to the planned and sustainable growth of the welfare of rural workers, the accelerated implementation of the export-oriented strategy, providing a multiplicative effect on the basis of large-scale innovative and technological modernization of agricultural sectors. The algorithm of estimation of efficiency of functioning of the integrated agricultural formations of the region reveals advantages of agricultural producers in the region of medium size, freely adapting to changing conditions and deprived of the shortcomings of large integrated groups and small sector.
\end{abstract}

\section{Introduction}

The ongoing market structural transformation of the domestic agricultural sector in the 90s of the last century led to the search for new most effective forms of coordination of intersectoral production and economic relations in the agro-industrial complex, focused on large-scale agribusiness. In the context of the accelerated solution of economic problems in the agricultural production sectors, it strengthens the vector of transformation of the economic mechanism towards large multi-disciplinary integrated formations. [1, 2, 3]. At the same time, the problem of explaining the phenomenon of the formation of their optimal size, development, efficiency and short-lived functioning is becoming more acute $[4,5,6]$.

\footnotetext{
* Corresponding author:kholodovama@rambler.ru
} 
To determine the optimal size of the functioning of integrated agricultural formations in the region, an evaluation algorithm is proposed, which includes two main stages. At the first stage, the role of large agricultural structures in the agricultural sector of the economy was revealed. The analysis of integration processes in the agricultural sector of the economy of the Rostov region is presented. The economic efficiency of the main types of integration agricultural associations of the Rostov region is investigated. In the second stage, based on a comparative analysis of the effectiveness of major agricultural groups using the groups depending on the area of agricultural land and the average number of employees and the linear matrix algebra the optimal size of modern Agroholding structures of the region.

\section{Research Result}

The current practice of economic activity in a large agricultural region in the south of the country-the Rostov region-indicates the strengthening of trends in the development and functioning of integrated formations in the agricultural sectors. To assess the efficiency of agricultural production in large agricultural formations in the region, the authors analyzed the results of their functioning in 2019. The rating of large integrated structures in agriculture of the Rostov region was headed by 8 organizations, the average annual number of employees of which is in the range from 423 people to 1920 people. They accounted for $85.3 \%$ of the profit from all agricultural enterprises in the region, $16.2 \%$ of the specific weight of the area of farmland, $16.6 \%$ of fixed assets, $16.9 \%$ of current assets, $16.3 \%$ of revenue and $14.8 \%$ of the number of employees from the general regional indicators. Out of the total number of research objects, 5 farms belonged to the type of vertical integration with crop and livestock production, 3 farms had a horizontal type of integration in the crop production industry.

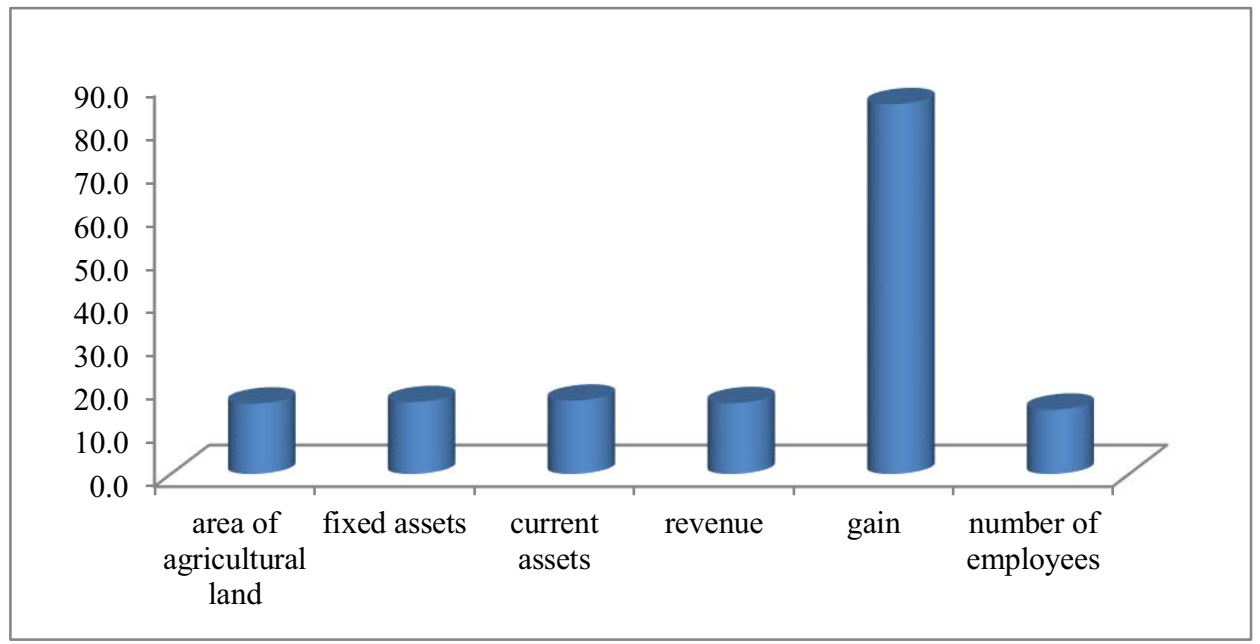

Fig. 1. The share of agricultural holding structures of the Rostov region in total indicators for agricultural organizations in $2019, \%$. Developed by the author based on the annual reports of agricultural enterprises of the Rostov region, 2019.

Let's compare the production parameters and production efficiency in the presented farms. Thus, the production potential of integrated formations of the horizontal type significantly exceeds its closest competitors. In particular, the vertical-type farms are more powerful and resistant to changing economic conditions in terms of parameters, and the horizontally integrated structures are superior to them in terms of the efficiency of production and economic activity in the conditions of the studied region. This trend is explained by the low profitability of the meat and dairy industries, which are actively developing with vertical 
integration. At the same time, on average, one integrated formation of the horizontal type accounted for agricultural land in the amount of 94595.9 hectares, current assets-3176,518 thousand rubles, the average annual number of employees was 941 people, which is higher than in the vertical type by $23.3 \%, 46.8 \%$ and $21.1 \%$, respectively (table 1 ). The level of gross profit of agricultural formations with a closed production cycle is 1.9 times lower than that of horizontal ones, and the equipment with energy capacities is 2.3 times lower, respectively. Indicators of economic efficiency of land use are also higher in horizontal formations $[7,8,9]$.

Table 1. Production parameters and efficiency of production and economic activity of large integrated formations of various types in the Rostov region in 2019, on average per 1 farm.

Developed by the author based on the annual reports of agricultural enterprises of the Rostov region, 2019.

\begin{tabular}{|c|c|c|}
\hline Indicator & $\begin{array}{c}\text { Integrated } \\
\text { vertical-type formations }\end{array}$ & $\begin{array}{c}\text { Integrated } \\
\text { formations of the } \\
\text { horizontal type }\end{array}$ \\
\hline Number of farms. units & 5 & 3 \\
\hline Fixed assets. thousand rub. & 3649257.94 & 3437816.67 \\
\hline Current assets. thousand rub. & 2163684.00 & 3176518.00 \\
\hline Revenue. mln rub. & 1651905.00 & 3473747.33 \\
\hline Net profit( loss). thousand rubles & 425693.40 & 802020.33 \\
\hline Area of farmland. ha & 76715.80 & 94595.87 \\
\hline $\begin{array}{l}\text { Average annual number of } \\
\text { employees. people }\end{array}$ & 777.00 & 941.00 \\
\hline Labor costs. person-hour & 1284.00 & 2593.85 \\
\hline Energy capacity. hp & 66570.00 & 151646.67 \\
\hline Profitability & 41.10 & 44.55 \\
\hline \multicolumn{3}{|l|}{$\begin{array}{l}\text { It accounts for } 100 \text { hectares of } \\
\text { agricultural land }\end{array}$} \\
\hline - labor costs. people-hours & 1.67 & 2.74 \\
\hline - cash revenue. thousand rub. & 2153.28 & 3672.20 \\
\hline - fixed assets. thousand rub. & 4756.85 & 3634.21 \\
\hline - net profit (loss) thousand rub. & 554.90 & 847.84 \\
\hline \multicolumn{3}{|l|}{ Accounts for 1 employee: } \\
\hline - cash revenue. thousand rub. & 2126.00 & 3691.55 \\
\hline - net profit (loss) thousand rub. & 547.87 & 852.31 \\
\hline $\begin{array}{l}\text { worked by } 1 \text { employee person- } \\
\text { hour }\end{array}$ & 1.65 & 2.76 \\
\hline Average monthly salary. rub. & 31136.46 & 31240.70 \\
\hline
\end{tabular}

Despite the fact that the indicators of commodity output and net profit per employee demonstrate significant advantages of horizontally integrated structures, the level of remuneration in this category of farms does not differ from those with vertical integration $[10,11,12]$.

A fairly high level of profitability in integrated forms of both types is due to a significant level of state support for this category of farms, since the state expects their activities to implement the course taken to ensure food security and the speed of "cutting" new "export windows" within the framework of an export-oriented strategyIn order to identify the relationship between the size of integrated formations and the efficiency of land use, the author uses the method of statistical grouping. The results of the grouping allowed us to distinguish four groups of farms with an area of agricultural land: Group I-up to 50,000 ha, group II - from 51,000 ha to 100,000 ha, group III - from 101,000 ha to 150,000 ha, group IV-over 150,000 ha. Comparative economic analysis between the groups was carried out according to the following evaluation criteria: the level of labor costs, thousand people. h., 
cash income, thousand rub.., fixed assets, thousand rub., net profit (loss) thousand rub. per 100 ha of agricultural land, level of cash revenue, thousand rub., net profit (loss) thousand rub., worked by 1 employee thousand people-hours per 1 employee, level of profitability,\%, size of average monthly salary, rub.

The analysis showed that in the integrated formations of group II and III, cash revenue and net profit per 100 hectares of farmland account for more than in the formations of group I and IV. The current situation is explained by the fact that the complex multi-level hierarchical structure of a large-scale management business does not allow for effective and organic use of the existing potential. In addition, in the formations of groups I, II, and III, the indicators of fund return and fund availability were significantly higher than in the formations of group IV. Farms with a total area of agricultural land of over 150,000 hectares are the leaders in terms of the level of labor stock ratio. The highest level of remuneration was recorded in the farms of group I (Fig. 2).

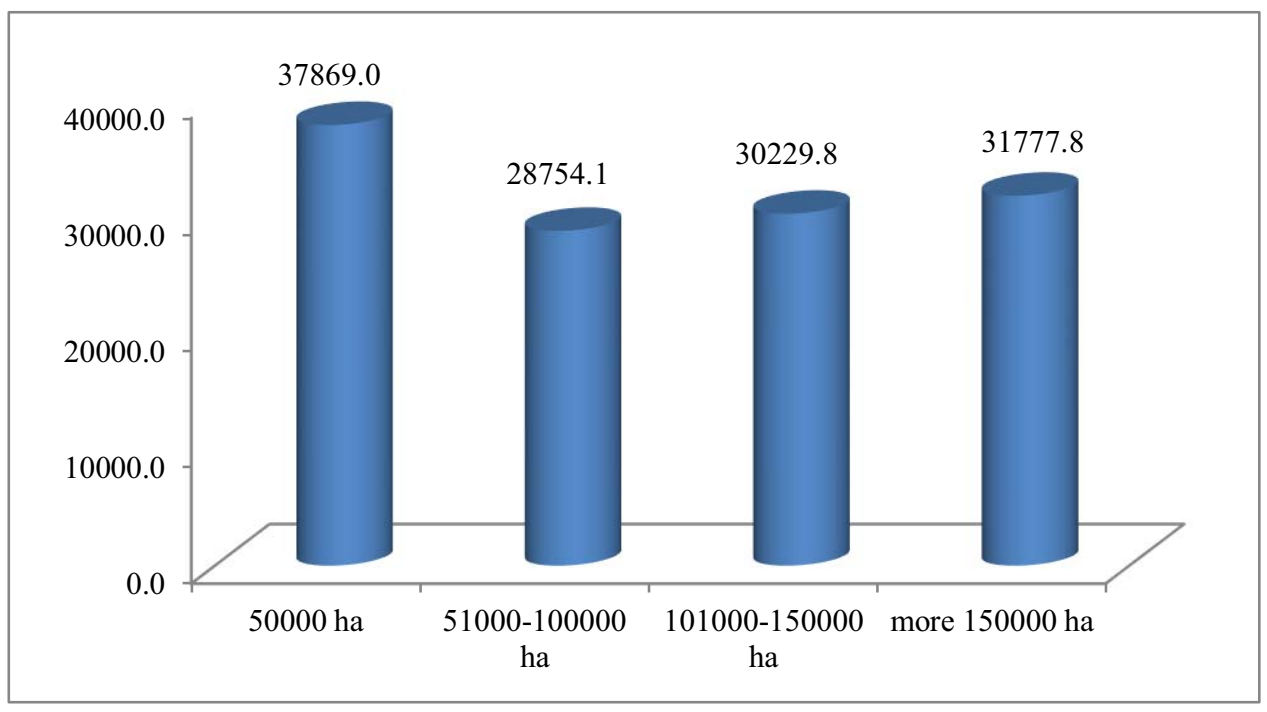

Fig. 2. The level of remuneration in integrated formations of the Rostov region, depending on the area of agricultural land in 2019, rub. Developed by the author based on the annual reports of agricultural enterprises of the Rostov region, 2019.

Standard of power and energy capacities of labour households in group I of the inferior forces of the III group (Fig. 3), this fact is due to the fact that large farms, a significant part of the area, removed the hired equipment, distilled from other divisions, which significantly facilitates harvesting companies and reduces the cost of production by the amount of investments in machinery industry $[13,14,15,16]$. 

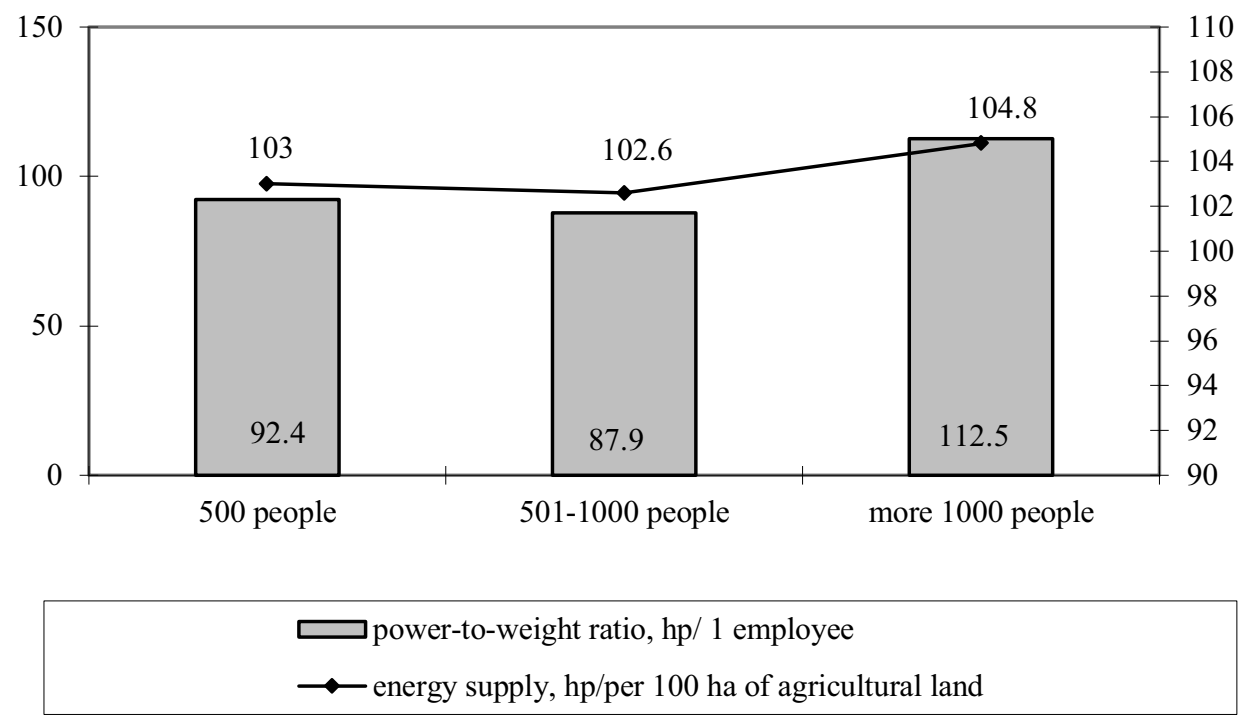

Fig. 3. The level of energy availability and energy supply in integrated formations of the Rostov region, depending on the average annual number of employees, 2019. Developed by the author based on the annual reports of agricultural enterprises of the Rostov region, 2019.

On the scale of Russian agriculture, this negative trend does not allow the economy to switch to innovative development tracks, and slows down the formation of a new technological way of life

The Achilles ' heel of agriculture in modern Russia continues to be the insufficient number of medium-sized agricultural producers that freely adapt to changing economic conditions and are devoid of the disadvantages of large integrated formations and the small-format sector. To determine the overall efficiency of the functioning of large integrated formations of the Rostov region in 2019 in the context of vertically and horizontally integrated structures, grouped by the area of farmland and the average annual number of employees, we conducted their ranking using the tools of multidimensional matrix analysis using elements of linear and vector-matrix algebra $[5,7,15]$.

The input parameters for constructing the matrix model of the rating of agricultural formations were indicators that include the average values of the production and economic activity of the studied enterprises by group.

Then the results of the calculations were raised to the second degree (Tables 8, 9, 10), summed up by columns and revealed the rating ratings of various integrated formations according to the formula:

$$
R=\left(x_{1}+x_{2}+x_{3}+\ldots+x_{n}\right)
$$

where $\mathrm{R}$ is the rating of the integrated formation,

$\mathrm{x} 1, \mathrm{x} 2, \mathrm{x} 3, . . \mathrm{cp}-$ the value of the estimated indicatorOur research shows that, according to the type of integration, the highest rating number belongs to horizontal structures with a total area of agricultural land from 51,000 ha to 100,000 ha and an average number of employees up to 500 people (Table 2).

Table 2. Rating model for assessing the effectiveness of integrated agricultural formations in the Rostov region, 2019. Developed by the author based on the annual reports of agricultural enterprises of the Rostov region, 2019. 


\begin{tabular}{|l|c|}
\hline \multicolumn{1}{|c|}{ Assessment criterion } & $\begin{array}{c}\text { Rating the } \\
\text { number }\end{array}$ \\
\hline \multicolumn{2}{|c|}{ type of integration } \\
\hline vertical type & 5.9 \\
\hline horizontal type & 8.89 \\
\hline \multicolumn{2}{|c|}{ area of agricultural land. ha } \\
\hline 50000 ha & 3.80 \\
\hline $51000-100000$ ha & 5.27 \\
\hline $101000-150000$ ha & 4.49 \\
\hline more 150 000 ha & 1.18 \\
\hline & \\
\hline 500 people & 5.73 \\
\hline $501-1000$ people & 3.86 \\
\hline more 1000 people & 5.48 \\
\hline
\end{tabular}

\section{Conclusion}

Thus, large-scale development of large integrated structures of this type in the sectors of agriculture guarantees a stable income growth and well-being of workers in rural areas, the rapid increase production of staple foods, providing a multiplier effect on the basis of innovation and technological modernization of agriculture.

\section{References}

1. V. Uzun, N. Shagaida, Z. Lerman, Land Use Policy 83, 475-487 (2019) doi: /10.1016/j.landusepol.2019.02.018

2. L.N. Usenko, Y.G. Chernysheva, V.A. Guzey, O.M. Todorova, A.M. Usenko, International journal of trade and global markets 2-3, 160-167 (2017) doi: 10.1504/ijtgm.2017.086074

3. S.K. Wegren, Journal of Eurasian Studies 3(2), 193-202 (2012) doi: 10.1016/j.euras.2012.03.010

4. M.Y. Anokhina, A.V. Golubev, O.N. Kondrashina, Journal of Environmental Management and Tourism 1(33), 119-134 (2019) doi: 10.14505/jemt.v10.1(33).12

5. N. Shagaida, V. Uzun, Growth drivers and structural shifts in Russian agriculture (Delo, Moscow, 2019)

6. A.N. Maloletko, G.I. Andryushchenko, O.V. Kaurova, E.A. Mityushina, A.A Shatskii, ESPACIOS 38(49), 19-21 (2017)

7. A.V. Tkach, G.N. Dudukalova, A.S. Nechitaylov, Complex Systems: Innovation and Sustainability in the Digital Age 1, 437-447 (2020)

8. L. Matraeva, O. Kaurova, E. Vasiutina, S. Erokhin European Research Studies Journal 21(3), 206-217 (2018)

9. O.A. Kholodov, Bulletin of agrarian science 4, 145-154 (2019)

10. R.F. Gataullin, A.A. Askarov, G.N. Khuzhakhmetova, N.V. Yarkov, Economic Region 2, 271-284 (2015) doi 10.17059/2015-2-22

11. I. Boldyreva, O. Andryushchenko, A. Nikitaeva, Z. Udalova, J. Rudash, Journal of environmental management and tourism 4(20), 642-647 (2017) doi:10.14505/ jemt.v8.3(19). 15

12. V.N. Minaev, Scientific Herald YUIM 2, 74-81 (2018) 
13. N.G. Vozhdaeva, I.V. Volkov, V.A. Kozlov, A.V. Pavlov, Azimuth of scientific research: Economics and management 8.2 (27), 103-108 (2019)

14. N.N. Lipatova, Intelligence. Innovation. Investment 1, 43-50 (2020) doi: $10.235198 / 2077-7175-2020-1-43$

15. A.A. Dibirov, O.A. Pogodina, O.V. Evolutionary, Russian electronic scientific journal 1(35), 243-257 (2020)

16. A.F. Maximov, Economics, labor, and management in agriculture 6(39), 69-75 (2018) 